\title{
A construção de uma Didática da História: algumas idéias sobre a utilização de filmes no ensino
}

Katia M aria ABUD ${ }^{1}$

RESU Mo: Desde as primeiras décadas do século XX, educadores preconizam a utilização do cinema como importante recurso didático no ensino de História, al guns ancorados na idéia de reprodução fiel do acontecimento passado. Mas, além disso, o cinema cria possibilidades de construção do conhecimento histórico escolar, pois o filme em sala de aula mobiliza operações mentais que conduzem o aluno a elaborar a consciência histórica, forma de consciência humana relacionada imediatamente com a vida humana prática, e que se constitui, em última instância, no objetivo maior do ensino deHistória.

palavra S-chave: educação, ensino de História; cinema.

Este texto pretende trazer à discussão algumas questões relativas à utilização do cinema como um recurso didático para o ensino de História. Entre todos os meios de comunicação, tem sido o cinema o que mais tem despertado o interesse dos professores por sua utilização em sala de aula.

Alguns fatores podem ser apontados como responsáveis por essa preferência: a enorme atração que a produção fílmica ainda exerce , a disseminação e a acessi bilidade das fitas de vídeo, tanto em locadoras como nas videotecas de instituições educativas e nas próprias escolas. Por outro lado, a utilização de filmes tem sido facilitada pelas políticas públicas que têm como proposta a educação a distância e tem fornecido às escolas os aparelhos para a projeção de programas ligados ao projeto: tel evisão e vídeocassete, utilizáveis também para a exibição de filmes em fitas de vídeo. 
No entanto, toda essa difusão não tem levado a uma discussão mais ampla sobre o uso do cinema nas aulas da escola básica, embora seja ele um dos elementos constitutivos de uma nova metodologia para o ensino de História.

O final da década de 70 e o início dos anos 80 do século passado foram marcados por mudanças de paradigmas e por novas propostas para a construção do conhecimento histórico. Desnecessário seria aqui a retomada do significado da N ova História e da re-afirmação das concepções dos Annalles, que deram novos contornos à produção historiográfica, que em última instância é a pedra fundamental sobre a qual se assenta o conhecimento histórico escolar. Às fontes tradicionalmente já consagradas pela Escola M etódica se aliaram outras, que fizeram desenvolver novas temáticas e novas formas de abordagem da H istória. Conceitos e categorias explicativas, como cotidiano e mentalidade, foram incorporados à produção historiográfica.

A História, como disciplina escolar, também é histórica. Isto é, também ela, como campo de conhecimento, passa por mudanças e transformações que a fazem filha do seu tempo. As novas abordagens, os novos objetos, outras fontes, outras linguagens foram se incorporando ao ensino de H istória. As novas ten dências e as correntes historiográficas que entendem a H istória como construção, aliadas a concepçõesqueenvolvem o processo deensino-aprendizagem, provocaram transformações bastante profundas na construção da H istória como conhecimento escolar. Tais transformações produziram modificações na Didática da H istória e provocaram uma reformulação na prática pedagógica. É necessário que se destaque a introdução e a permanência, nos documentos curriculares, de orientações sobre o uso das novas linguagens, a despeito da inércia da organização escolar no sentido de consolidá-las como práticas cotidianas.

A produção fílmica passou a ser considerada de importância para a construção do conhecimento histórico e do saber escolar a partir da década de 70. Marc Ferro nos lembra que o cinema nasceu depois da História, quando esta já tinha hierarquizado suas fontes, colocando entre elas os documentos de Estado, textos jurídicos e legislativos, jornais e publicações, fontes orais da história local, literatura de viajantes. 
As fontes consagravam o ponto de vista daqueles que se responsabilizavam pela sociedade: homens de Estado, diplomatas, magistrados, empresários e administradores. ${ }^{2} \mathrm{~A}$ recusa inconsciente dos historiadores em aceitar a importância dos que não detinham o poder, fez com que o filme não estivesse entre os documentos a serem transformados em monumentos.

A aceitação do filme como documento resulta do abandono da concepção de História da escola metódica, concepção esta que tem sua ruptura marcada, sobretudo a partir da obra de M arc Bloch e Lucien Fèbvre e da fundação da revista Annalles: Anais de H istória Econômica e Social. Este grupo pode ser apontado como responsável pelo desenvolvimento de um novo modo de produção historiográfica, no qual o historiador fabrica seu objeto e ele mesmo é sujeito na produção da História: constrói e recorta seu objeto de estudo. Com isso, a concepção de que é possível que a verdade absoluta e atemporal surja dos estudos de história sofreu um forte abalo. 0 restabel ecimento da verdade dos fatos à sua realidade original, o fetichismo dos acontecimentos passou a ser combatido pelos críticos da História “historicizante", que propunham a H istória-problema como substituta da História dos reis, tratados e batalhas.

A História escrita pelos historiadores dos Annalles indicou novos caminhos para a História, e no pós-guerra, no "período que cobre os anos 50 e 60, pelo menos duas correntes desdobram-se das propostas francesas: a da chamada história social e a da história das mentalidades". ${ }^{3}$ Destas, foi a H istória das M entalidades a que mais se desenvolveu nas duas últimas décadas. Segundo Le Goff, ela teria se desenvolvido graças ao esgotamento de determinados conceitos e correntes historiográficas que, paralelamente à produção histórica dos Annalles, tinham se desenvolvido no século XX. Tais correntes dariam demasiado peso a conceitos e categorias, ou se prenderiam muito fortemente ao aspecto quantitativo.

No mesmo período em que os Annalles iniciavam o processo de renovação da produção historiográfica, expandiam-se idéias que propunham inovações para o desenvolvimento educacional. Nos Estados Unidos, Suíça, França e Itália, educadores e estudiosos da Psi cologia 
da Aprendizagem opunham-se às práticas pedagógicas tidas como tradicionais, visando a uma educação que pudesse integrar o indivíduo na sociedade e, ao mesmo tempo, ampliasse o acesso de todos à escola. Reconheciam que as transformações pel as quais a sociedade ocidental passava exigiam a utilização de diferentes métodos de ensino que enfatizassem o lado criativo do aluno e as possibilidades de participação na elaboração do conhecimento. A noção de que cabia à criança descobrir o conhecimento por meio dos sentidos, eque era a partir do trabalho em sala de aula, ou em atividades extraclasse que o saber deveria ser construído pelo aluno, individual e coletivamente, pesava na organização das propostas metodológicas para o ensino. As novas tecnologias eram apontadas como recursos didáticos para o desenvolvimento dessa Escola Nova, como passou a ser denominado o conjunto deidéias que combatia o ensino tradicional.

No Brasil, os defensores das propostas da Escola Nova sugeriam a utilização dos recursos audiovisuais, em especial do cinema (que havia tido um espetacular desenvolvimento nas décadas de 10 e 20), como uma maneira de estimular e tornar o processo de aprendizagem interessante para o educando. ${ }^{4}$ As Instruções M etodológicas el aboradas para auxiliar a aplicação dos programas de H istória para a escola secundária, impostos a todos os estabelecimentos escolares brasileiros, logo após a Reforma Francisco Campos (Decreto 19.890 de 1931), recomendavam a utilização da iconografia. Alegavam que os adolescentes tinham uma curiosidade natural pela imagem, e que por este motivo os recursos tecnológicos deveriam ser utilizados no ensino secundário.

Seguindo as novas propostas, e também com o intuito de controlar a influência que o cinema exerceria sobre a juventude, a Lei $\mathrm{n} 0$ 378, de 13/1/1937, criou o Instituto Nacional de Cinema Educativo (INCE), que teve como primeiro diretor o médico, professor e pioneiro das comunicações Roquette Pinto. O IN CE produziu, logo no início de seu funcionamento, dois filmes sobre a H istória do Brasil: 0 descobrimento do brasil e Os bandei rantes, ambos dirigidos por Humberto Mauro. As produções do cinema educativo, que tinham como finalidade instruir a juventude sobre a nossa história, acatavam os princípios da H is- 
tória oficial, e se por um lado pareciam servir aos objetivos da Escola Nova, por outro ajudavam a sacramentar mitos nacionais. ${ }^{5}$

Compactuando com os paradigmas da Escola M etódica, professores escolanovistas, que viam o cinema como um grande atrativo para os alunos, defendiam o uso do cinema educativo, desde que fosse para garantir a verdade histórica, que corria sérios riscos de ser deturpada pelos filmes históricos, pois como afirmava Jonathas Serrano: “(D) eforma-se deliberadamente o passado para efeitos românticos, ou cômicos, e o público aplaude e... desaprende o que sabia ou aprende errado para o resto da vida." ${ }^{6}$

Serrano não é uma voz isolada. Partilha suas idéias com outros professores brasileiros e de outros países, que buscam modernizar 0 ensino para que os alunos aprendam os verdadei ros conteúdos das disciplinas, como A. Sluys, diretor honorário da Escola Normal de Bruxelas que, numa obra traduzida e adaptada para o espanhol por Agustín Nogués Sarda, inspetor de ensino de M adri, afirma:

No ensino de História pelo cinema se empregam figurantes para representar os acontecimentos históricos. Isso é reclamar por parte dos alunos uma docilidade, ou melhor, um servilismo de espírito pouco corrente em crianças latinas. Poderia passar por um espetáculo, porém não por uma lição que tem por fundamento a verdade. ${ }^{7}$

Serrano também reconhece valor educativo exclusivamente se o filme for uma fonte histórica, ou seja, quando consegue fazer

o fato reproduzir-se na sua complexa realidade. M as somente na hipótese de haver sido filmado no próprio instante em que ocorria: filmes documentais de guerra, de expedições científicas, jornais cinematográficos, etc. (...) M as, reconstruir o passado nos chamados filmes históricos, isso é obra da imaginação. ${ }^{8}$

Admite que um outro gênero de filmes poderia prestar relevantes serviços ao ensino de H istória: a filmagem de excursões a locais históricos e os comentários correspondentes feitos por especialistas. 
Não deixa de ser instigante o fato de que décadas antes de os historiadores aceitarem o cinema entre suas fontes, professores de H istória já pensassem nas possíveis utilidades do cinema em sala de aula. Digno de nota é também o conservadorismo em relação à produção histórica enten dida como reprodução da verdade, quando a concepção da H istória acadêmica já passava por tran sformações e a concepção de ensino continuava sendo considerada mera transposição, uma linguagem simplificada da verdade contida pela narração histórica. Isso apesar da aceitação pelos mesmos professores dos novos paradigmas da Escola Nova em relação à aprendizagem.

A análise da restrita produção fílmica aceita pelos educadores se relaciona única e exclusivamente ao conteúdo. 0 cinema seria um bom recurso, pois atrairia a atenção dos jovens mais que as aulas e exposições orais realizadas pelo professor em sua sala de aula. $N$ ão se trata ainda de encarar a linguagem imagética como um recurso com características próprias, nem de propor métodos de trabalho pedagógico com a exploração das imagens. Como elas têm suas próprias regras de funcionamento e atualizam um conjunto de configurações significantes especificamente icônicas, ao serem analisadas permitem quese compreenda melhor os aspectos que os currículos escolares propõem. Processam, ainda, outros símbolos amplamente culturais e sociais, mediante os quais apresentam uma certa imagem do mundo, que devem possibilitar ao aluno que desenvolva a análise crítica do mundo no qual vive. Além disso, acarreta outras instâncias de referências, como comportamentos, moda, vocabulário. As imagens merecem estar em sala de aula porque sua leitura nunca é passiva. Elas provocam uma atividade psíquica intensa feita de sel eções, de relações entre elementos da mesma obra, mas também com outras imagens e com representações criadas e expressas por outras formas de linguagem. A imagem fílmica situa-se em relação à outra, ausente, que se relaciona com a realidade que se supõe representada.

Expressões que se tornaram já lugares comuns, como "uma imagem vale mais que mil palavras" dão segurança a professores, que são auxiliados pela existência, nas escolas, de retroprojetores, aparelhos de televisão, projetores de vídeo e outros instrumentos. A expressão não é 
vazia e nem carece de fundamento, pois estudos sobre o tema asseguram que os dados provenientes da visão e audição correspondem a $50 \%$ do que é retido pelos alunos. Audição e visão são também responsáveis pela retenção mais duradoura daquilo que os alunos aprendem. ${ }^{9}$ A retenção, embora necessária, não se constitui numa suficiente operação mental para posterior análise e construção do conhecimento histórico pelo aluno. Essa perspectiva demonstra que persiste a idéia da existência de um mundo positivo, real, que pode ser captado pelas imagens, daí a permanência da valorização dos documentários que teriam um compromisso maior com a realidade. 0 documentário e os filmes de época ou históricos têm, para a maior parte dos professores que utilizam a filmografia em sala de aula, o mesmo valor didático de um texto de um livro de História. ${ }^{10} \mathrm{O}$ filme é mais utilizado como um substituto do texto didático ou da aula expositiva, ou éainda considerado uma ilustração que dá credibilidade ao tema que se está estudando.

Contudo, "é certo que hoje se admite que a imagem não ilustra nem reproduz a realidade, ela a constrói a partir de uma linguagem própria que é produzida num dado contexto histórico". ${ }^{11}$ Do mesmo modo, quando utilizado em atividades didáticas, não se limita a traduzir em imagens os conteúdos pedagógicos reificados. Dono de uma identidade própria, como documento histórico que exige instrumental adequado para sua exploração, o filme na aula de H istória na escola básica também exige uma proposta didática. Há, primeiramente, que se diferenciar a formação da informação. A maior parte das vezes em que o filme é utilizado, busca-se o maior número de informações sobre um fato histórico, um personagem. A informação pode ser definida como um pensamento que existe em algum lugar, no tempo e no espaço, e a formação como uma série de ações que apontam para um resultado. No entanto, o filme é pouco utilizado para a formação, que só pode ocorrer quando a informação recebida se relaciona com um conjunto individual de esquemas e de estruturas mentais, que transforma a informação em conhecimento, em novos esquemas e novas estruturas que irão enriquecer o repertório cognitivo ou simbólico daquele que aprende. A formação é um processo de produção no qual se destacam dois aspectos: o primeiro éo das operações medianteas quais 
o conhecimento é gerado, e o segundo são os condicionantes que facilitam a geração desse conhecimento.

A linguagem própria da imagem auxiliará na construção do conhecimento histórico do aluno, construção esta que passa por elaboração de operações mentais, para resultar em efeitos sociais, como os enumerados por Jean Peyrot, citado por Henri Moniot:

- transmitir uma memória coletiva, revista e corrigida a cada geração, que coloca o aluno diante de uma consciência coletiva;

- formar a capacidade de julgar - comparando sociedades em épocas diferentes, e a existência delas ao mesmo tempo em locais diferentes - que tem como efeito social o desenvolvimento do espírito crítico e da tolerância;

- analisar uma situação - aprendendo a isolar os componentes e as relações de força de um acontecimento ou de uma situação - que leva ao refinamento do espírito, antídoto ao simplismo de pensamento;

- formar a consciência política como instrumento de coesão social, memória de um grupo que toma consciência de um destino comum. ${ }^{12}$

Os efeitos sociais da aprendizagem de H istória se sintetizam e se consolidam na consciência histórica que, segundo Rusen, é a forma de consciência humana que está relacionada imediatamente com a vida humana prática:

se entende por consciência histórica a soma das operações mentais com as quais os homens interpretam sua experiência da evolução temporal de seu mundo e de si mesmos de forma tal que possam orientar, intencionalmente, sua vida prática no tempo. ${ }^{13}$

A análise do documento textual na sala de aula segue orientações próprias, destinadas a atender suas especificidades. 0 mesmo tipo de procedimento é recomendado quando se trata da utilização de um documento fílmico. À semelhança da produção escrita, a filmica tem si- 
do, com muita freqüência, utilizada como uma ilustração que sustenta a análise do professor, garantindo aos alunos que a fala do professor é verdadeira. 0 professor pode também, pelo caminho indutivo, valerse do documento como elemento intermediário que transmite aos alunos aquilo que se pretender ensinar, atribuindo-Ihe um sentido próprio. Este é o percurso que permite uma efetiva atividade intelectual do aluno, feita de curiosidade e de espírito crítico e que confere sentido ao saber histórico escolar.

Tendo como modelo o documento escrito, pode-se afirmar que quando alguém assiste a uma produção cinematográfica, vale-se de um conjunto de orientações para construir representações mentais do significado que o filme possa Ihe despertar. Se a inteligibilidade do texto verbal faz uso principalmente de representações mentais de natureza lingüística, como conceitos, proposições e também representações de imagens, a análise do texto fílmico, que mobiliza principalmente as representações imagéticas, não pode dispensar as de natureza lingüística. De acordo com Sultan, ${ }^{14}$ estudiosos dos processos de cognição, como Pavio, consideram que as atividades psicológicas do indivíduo se regem paralelamente por dois sistemas de codificação: o sistema de representações imagéticas, no qual o desenvolvimento se relaciona à experiência perceptiva, eo sistema de representações verbais, que se constroem por meio da linguagem. Em ambos, as representações mentais mobilizadas por um indivíduo dependem das competências que ele pode desenvolver em relação a cada um dos modos de expressão.

$\mathrm{N}$ a perspectiva acima, pode-se afirmar que o filme promove o uso da percepção, uma atividade cognitiva que desenvolve estratégias de exploração, busca de informação e estabelece relações. Ela é orientada por operações intelectuais, como observar, identificar, extrair, comparar, articular, estabelecer relações, sucessões e causalidade, entre outras. ${ }^{15}$ Por esses motivos, a análise de um documento fílmico, qualquer que seja seu tema, produz efeitos na aprendizagem de História, sem contar que tais operações são também imprescindíveis para a inteligibilidade do próprio filme.

Ao proceder às operações mentais necessárias para a inteligibilidade do filme, o aluno estará elaborando o seu pensamento histórico 
na perspectiva de construção da consciência história, não elaborando as técnicas e os procedimentos da profissão de historiador, mas os elementos fundamentais do modo de pensar que habita intimamente as proposições históricas, que as informa e as torna significativas, distinguindo a H istória das maneiras ligeiras e espontâneas de representar o passado.

ABUD, K. M . Theconstruction of a Didactic of History: someideas about the utilization of movie on teaching. História. São Paulo, v.22, n. 1, pp. 183 a 193, 2003.

\begin{abstract}
A Bstract: Since the first decades of the 20th century, educators advocate the utilization of cinema as an important didactic resource in the $\mathrm{History}$ teaching, some pointing out the idea of faithful reproduction of the past. Cinema creates possibilities to build the school historical knowledge, once the movie, seen in classroom, mobilizes mental operations that makes the student to elaborate the historical conscience, that is a way of human conscience immediately related with the practical human life, and that is, at least, the hugest objective of History teaching.
\end{abstract}

KEY wO RDs: Education, teaching History, cinema.

\title{
NOTAS
}

${ }^{1}$ Faculdade de Educação - USP - 05508-900 - São Paulo - SP.

${ }^{2}$ FERRO, M 0 filme. Uma contra-análise da sociedade. In: LE GOFF; J. NORA, P. História: novos objetos. Rio de Janeiro: Francisco Alves, 1976, pp. 199-215.

${ }^{3}$ SALIBA, E.T. A produção do conhecimento histórico e suas relações com a narrativa fílmica. São Paulo: FDE-Diretoria Técnica, 1992, p.14 (grifos no original).

${ }^{4}$ SERRAN O, J. \& VENÂNCIO F. F. O cinema educativo. Escola N ova. São Paulo, v. 3, n. 3, jul.1931. FRAN CO, M. da S. F. A natureza pedagógica das linguagens audiovisuais. São Paulo: FDE, 1992. M enciona ainda outra obra dos dois autores citados: Cinema e Educação, publicada em 1930, e a de Canuto M endes de Almeida, Cinema contra Cinema, de 1931.

${ }^{5}$ O INCE existiu até 1966, quando setransformou no Departamento de Filme Cultural do Instituto Nacional de Cinema (INC), também já extinto. 
${ }^{6}$ SERRAN O, J. Como se ensina História. São Paulo: M elhoramentos, 1935, p. 112.

${ }^{7}$ SLUYS, A. La cinematografia escolar y post-escolar. Traducido eadaptado a las proyecciones fijas y animadas por Agustín Nogués Sarda. Madrid: Ediciones de La Lectura, 1925, p. 78 (tradução da autora).

${ }^{8}$ SERRAN O, J. Op. cit., p. 112.

${ }^{9}$ PROEN ÇA, M. C. Ensinar/A prender História: questões de didática aplicada. Lisboa: Livros H orizonte, 1990, p. 106.

${ }^{10}$ Embora não haja uma pesquisa criteriosa sobre o assunto, os rel atórios de alunos estagiários de M etodologia de Ensino de História indicam que os professores que projetam filmes em suas aulas escolhem-nos como complementos do conteúdo. 0 nome da rosa ajuda a explicar o feudalismo, o poder da I greja, a Inquisição; 0 que éisso, companheiro, a ditadura militar; Q uilombo, a escravidão e a resistência; Carlota Joaquina, o processo de Indepen dência.

${ }^{11}$ SALIBA, E. T. Experiências erepresentações sociai s: reflexões sobre o uso eo consumo de imagens. In: BITTEN COURT, C. (org.). 0 saber histórico em sala de aula. São Paulo: Contexto, 1997, pp. 117-127.

${ }_{12}$ PEYROT, J. Historiens et géographes, décembre 1983, pp. 285-6. Apud: M ONIOT, H. Didactique de l'H istoire. Paris: Nathan Pédagogie, 1993, p. 21.

${ }^{13}$ RUSEN , J. Razão histórica: teoria da história: fundamentos da ciência histórica. Brasília: Editora Universidade de Braślia, 2001, p. 57.

${ }^{14}$ SU LTAN, J. Faire l'image: une activité de connaissance. Eléments pour un cadre théorique. In: POIRIER, B.; SU LTAN, J. (Dir.) Faire/voir e savoir: connaissance de I'image, image et connaissance-images technologiques en arts plastiques et en histoire. Paris: IN RP, 1992, p. 23. (Rencontres Pédagogiques, 31).

${ }^{15}$ POIRIER, B. Voir, connaître et apprendre. In: POIRIER, B.; SU LTAN, J. O p. cit., p. 107.

Artigo recebido em 02/2003. Aprovado em 04/2003. 